\title{
Copper-zinc superoxide dismutase deficiency impairs sperm motility and in vivo fertility
}

\author{
Michael Garratt, Roslyn Bathgate ${ }^{1}$, Simon P de Graaf ${ }^{1}$ and Robert C Brooks \\ Evolution and Ecology Research Centre and School of Biological, Earth and Environmental Sciences, The University of \\ New South Wales, Sydney, New South Wales 2052, Australia and ${ }^{1}$ Faculty of Veterinary Science, The University of \\ Sydney, Sydney, New South Wales 2006, Australia
}

Correspondence should be addressed to M Garratt; Email: michael.garratt@unsw.edu.au

\begin{abstract}
Oxidative stress, overproduction of reactive oxygen species (ROS) in relation to defence mechanisms, is considered to be a major cause of male infertility. For protection against the deleterious effects of ROS, animals have a variety of enzymatic antioxidants that reduce these molecules to less reactive forms. The physiological role of these antioxidants in vivo has been explored extensively through genetic inhibition of gene expression; surprisingly, many of these animals remain fertile in spite of increased oxidative stress. Copper-zinc superoxide dismutase-deficient $\left(\operatorname{Sod}^{-/-}\right)$male mice are one such example for which in vivo fertility has been repeatedly reported as normal, although examination of fertility has consisted of simply pairing animals of the same strain and checking for litters. This is a fairly low criterion by which to assess fertility. Herein, we show that Sod1-deficient males have zero fertilisation success in sperm competition trials that pit them against wild-type males of an otherwise identical genetic background and are almost completely infertile when mated singly with females of a different genotype. We also show that various aspects of sperm motility and function are impaired in Sod1-deficient mice. Testing the breeding capabilities of mice under more ecologically relevant conditions and with females of different genotypes may help reveal additional physiological causes of infertility.

Reproduction (2013) 146 297-304
\end{abstract}

\section{Introduction}

Reactive oxygen species (ROS) are produced from a variety of sources in biological systems (Beckman \& Ames 1998). ROS have important signalling roles, but when unregulated, they can impair cellular function, cause oxidative damage to biomolecules and limit the ability to regulate gene expression (Droge 2002). For protection against the deleterious effects of ROS, organisms have a variety of enzymatic and nonenzymatic defences. Endogenous enzymatic antioxidant defences with an established role in vivo include superoxide dismutase (SOD), catalase and glutathione peroxidase (GPX; Halliwell \& Gutteridge 1999). Dietary molecules such as vitamin $\mathrm{E}$, vitamin $\mathrm{C}$ and carotenoids may also help protect against the overproduction of ROS, although their antioxidant role in vivo is less well established (Halliwell \& Gutteridge 1999).

Spermatozoa are especially susceptible to damage caused by ROS. The plasma membranes of spermatozoa have high levels of polyunsaturated fatty acids, making them very susceptible to ROS-induced damage (Alvarez \& Storey 1995). This damage can impair sperm function (Alvarez et al. 1987) and also cause further production of ROS. Spermatozoa contain relatively low levels of antioxidant enzymes (Agarwal et al. 2003) and are largely transcriptionally silent (Aitken \& Graves 2002), giving them less scope for protection against the damaging effects of ROS. In relation to ROS production, spermatozoa produce ATP to facilitate their motility, and this energy metabolism is a major source of ROS (Beckman \& Ames 1998, Koppers et al. 2008). Spermatozoa, therefore, seem especially prone to ROS-induced damage, and this damage could be particularly detrimental due to the heritable modification of the germ line through uncontrolled oxidation (Aitken et al. 2003).

A plethora of correlative evidence shows that spermatozoa are negatively affected by uncontrolled ROS production and insufficient antioxidant defence (reviewed in Sikka et al. (1995), Saleh \& Agarwal (2002) and Agarwal et al. (2003)). To determine the direct role of antioxidant defence in sperm function, genetic modification of gene expression has been used to impair the synthesis of antioxidant defence enzymes (Koppers 2012). Surprisingly, many knockout models of classic antioxidant defence enzymes have remained fertile, although additional oxidative challenges can sometimes reveal an effect on sperm motility or morphology (Koppers 2012). In Gpx knockout animals, fertility is 
dependent on the isoform in question, with Gpx1 and nuclear Gpx4 male mice apparently retaining normal fertility (Ho et al. 1997, Conrad et al. 2005). However, disruption of Gpx4 expression in the mitochondria leads to infertility in males when mated with a female of the same strain (Schneider et al. 2009).

SOD is sometimes described as the first and most important line of antioxidant defence (Zelko et al. 2002) and occurs in several different isoforms. While fully deficient manganese Sod mice $\left(\operatorname{Sod} 2^{-1-}\right)$ die prior to weaning, heterozygous Sod2-deficient mice $\left(\operatorname{Sod} 2^{+/-}\right)$ suffer from increased oxidative stress, but are apparently fertile (Koppers 2012). One of the most frequently used mouse models of oxidative stress and ageing is the copper-zinc Sod fully deficient mouse $\left(\operatorname{Sod} 1^{-/}\right)$. Sod1 knockout animals (Sod $1^{-/}$) exhibit an elevation in the levels of various markers of oxidative stress (Elchuri et al. 2005, Muller et al. 2006, Perez et al. 2009), but otherwise appear relatively normal under standard laboratory conditions (Reaume et al. 1996, Elchuri et al. 2007). The fertility of female Sod1 $1^{-1-}$ mice is greatly reduced, but three independent studies have reported that males are fully fertile when mated with C57BL/6 females (Ho et al. 1998, Matzuk et al. 1998, Tsunoda et al. 2012), the genetic background on which this knockout is usually maintained.

These studies, similar to virtually all of the above-cited examples, have simply paired males with a female of their own strain and allowed them to breed in isolation over several months. In the wild, males will mate with females of different genotypes and will also be required to compete with other males for fertilisation, as female mice regularly mate with more than one male in an oestrous cycle (Dean et al. 2006, Firman \& Simmons 2008). It has recently been demonstrated that Sod $1^{-1-}$ mice have a reduced fertility rate in vitro, due, at least in part, to an inability of sperm to penetrate the zona pellucida (Tsunoda et al. 2012). This suggests that SOD expression may influence fertility under particular conditions. Herein, we show that Sod $1^{-/-}$mice are almost entirely infertile when mated with the CBA strain of laboratory females, even though wild-type males $\left(\operatorname{Sod} 1^{+/+}\right)$mated at the same time with CBA females exhibit normal fertility. This is apparent when a male of each genotype (both Sod1 $1^{-/-}$and $\operatorname{Sod} 1^{+/+}$) is mated with the same female and sperm compete to fertilise a female's eggs (Parker 1970) and when each male is mated singly with separate females. This reduction in fertility is accompanied by various impairments in sperm motility and function.

\section{Materials and methods}

\section{Experimental animals}

Mice that did not express $\operatorname{Sod} 1\left(\operatorname{Sod} 1^{-/}\right)$and their wild-type littermates $\left(\operatorname{Sod} 1^{+/+}\right)$were maintained on a $\operatorname{C57\mathrm {BL}/6}$ background. The generation of this knockout strain has been reported previously (Muller et al. 2006, Kostrominova et al. 2007). The line of Sod1-deficient mice used in these experiments was derived from three pairs of $\operatorname{Sod} 1^{+/-}$mice imported from the Jackson Laboratories (Bar Harbor, ME, USA) and used to create a SPF breeding colony at the Australian BioResource Centre in Mossvale, NSW, Australia. When 6-8 weeks old, experimental Sod1 mice were transported and housed in conventional facilities at the University of New South Wales (UNSW). The mice were maintained at $22 \pm 2{ }^{\circ} \mathrm{C}$ under a $12 \mathrm{~h}$ light: $12 \mathrm{~h}$ darkness cycle. All experimental procedures and mating trials were conducted in the dark period under dim red light. Males were housed singly in cages $(53 \times 35 \times 18 \mathrm{~cm})$ and were regularly exposed to the odour and presence of males and females of the CBA strain to ensure the development of normal reproductive behaviour. Food (stock feed from Gordon's Specialty Stockfeeds, Yanderra, NSW, Australia) and water were provided ad libitum. CBA females (CBA/CaHAusb) of 6-7 weeks of age were purchased from the Australian BioResource Centre, transported to the UNSW and then housed in groups of two to three until the start of the experiments. The CBA strain of females was used in these experiments because previous studies have shown that matings between CBA females and C57BL/6 males produce viable offspring (Hager \& Johnstone 2003, 2006) and these strains are derived from two different mouse lineages (Beck et al. 2000). All experimental procedures were approved by the UNSW animal ethics committee (approval number: 12/30A).

\section{Mating assays}

The sperm competition mating procedure was based on a previously published method (Firman \& Simmons 2011). A mixture of soiled bedding from the cages of both $\operatorname{Sod} 1^{+/+}$ and $\operatorname{Sod}^{-1-}$ males was placed into each female's cage three days prior to mating to induce oestrus (Marsden \& Bronson 1964). On the morning of the trial (i.e. the beginning of the dark period), oestrus was confirmed by vaginal smear (Allen 1922). Each female was then placed into the cage of the first male with which it was to mate (either a Sod $1^{-/-}$or a Sod $1^{+/+}$male) and checked at least every hour thereafter for the presence of a copulatory plug. When a plug was observed, the mouse was gently scruffed and the plug was removed using a blunt probe. The female was then placed into the second male's cage (the other genotype from the first male with which it had just mated), and it was checked every hour until a second plug was observed. The female was then transferred into a clean cage. Half the females were mated with the Sod $1^{-1-}$ male first and half with the Sod $1^{+/+}$male first.

Due to the relatively low propensity of male mating under such experimental conditions (Ramm \& Stockley 2007), we conducted a total of 160 mating trials, of which 64 resulted in at least one successful copulation. For 33 of these successful matings, the female was not mated with a second male, but placed straight into a clean cage. This allowed us to assess the fertility of males when not competing under sperm competition.

Eight homozygous and ten age-matched wild-type males were used in these mating trials. Males were 2 months old at 
the start of the experiments and $\sim 4.5$ months at completion. Each male was mated just once per week, and the experience that males accrued over the experiment was monitored to ensure that these two groups of males did not differ in their total sexual experience over the experiment.

\section{Dissection}

Females that successfully mated (to ejaculation) with a male were culled 14 days after mating using an overdose of carbon dioxide. Females were dissected, and the number of foetuses was counted and then a small tissue sample was taken from each foetus for genotyping. Paternity was assigned on the basis of whether foetuses were heterozygous for Sod1 (i.e. must have been parented by the homozygous male and CBA female) or wild type (parented by the wild-type male and CBA female). Genotyping was conducted by the mouse genotyping service at the Australian Cancer Research Foundation (ACRF), the Garvan Institute, using a combination of real-time PCR and melting curve analysis. At the end of the experiments, all experimental males were culled by cervical dislocation. Males were quickly dissected, and the reproductive organs were removed and weighed.

\section{Males used to assess sperm motility}

As it was apparent that the fertility of males was deleteriously affected by the loss of Sod1 expression, we examined sperm motility in a second set of males. These males were being used for a different experiment and were housed in a slightly different social environment. They were imported to the UNSW at the same age, housed in the same-sized cages and similarly exposed to CBA males and females. However, each mouse was housed in a cage with a $\operatorname{Sod} 1$ heterozygous $\left(\operatorname{Sod} 1^{+/-}\right)$male. The cage was divided by a perforated plastic barrier so that each male was unable to physically touch the other, but olfactory and visual contact was permitted. On ten occasions over a 2-week period, the barrier between the males was removed, and the males were able to interact physically for a 15-min period to allow the development of aggressive behaviour. Sperm motility was assessed in ten Sod1 ${ }^{-1-}$ males and nine Sod $1^{+/+}$males.

\section{Sperm motility analysis}

At the end of the experiments, males were culled by cervical dislocation. Males were quickly dissected, and the epididymides were removed and stored at $37^{\circ} \mathrm{C}$ until analysis of sperm motility, which commenced $1-3 \mathrm{~h}$ after the dissection. Sperm samples were prepared for the analysis of motility using a previously published method (Koyama \& Kamimura 1999). The right cauda epididymis was added to $100 \mu$ of Biggers, Whitten and Whittingham (BWW) medium (Koyama \& Kamimura 1999), and five cuts were made along its length. Sperm were allowed to swim out over a 5-min period, and then the epididymis was removed and an additional $400 \mu \mathrm{l}$ of BWW medium was added. A $5.5 \mu \mathrm{l}$ aliquot of the sperm suspension was added to a pre-warmed slide with a chamber depth of $20 \mu \mathrm{m}$ (Cell Vu; Millenium Sciences Corp., New York, NY, USA), and the motility parameters of 200-300 sperm were assessed with a computer-assisted sperm analyser (CASA; HTM-IVOS version 12: Hamilton Thorne, Beverly, MA, USA) using factory parameters (mouse 1) at a sampling frequency of $60 \mathrm{~Hz}$. The means of the kinetic parameters were obtained by averaging the summary values from each sample.

\section{Statistical analysis}

Generalised linear mixed-effects models were constructed to test for differences between Sod $1^{-/-}$and Sod $1^{+/+}$males using the Ime4 package in R. When testing for a difference in the number of foetuses, the models were fitted with a Poisson distribution. When testing whether females were either pregnant or not, the models were fitted with a binomial distribution. To test for an effect of genotype on sperm competition success, we assessed the percentage of offspring sired by the male in the offensive sperm competition position (Mueller et al. 2008, Firman \& Simmons 2011, Klemme \& Firman 2013). A binomial distribution was used when examining this percentage, because all values were either 100 or $0 \%$ (effectively either 0 or 1 ) due to Sod $1^{+/+}$males siring all the offspring regardless of being the first or second to mate. Male genotype was added as a fixed effect and male ID was added as a random effect to control for the nonindependence arising from using each male more than once. The significance of the genotype effect was tested by comparing models with and without the genotype term using a loglikelihood ratio test.

Differences between males with regard to the masses of reproductive organs were assessed in SPSS using General Linear Models. Differences in organ weights were assessed with body mass added as a covariate. Differences between males in sperm motility and related parameters were assessed using independent-samples $t$-tests.

\section{Results}

\section{Reduced fertility in Sod1-deficient males}

To ascertain whether Sod $1^{-/-}$males exhibit reduced fertility under more challenging mating conditions, we mated CBA females with both a Sod $1^{+/ 4}$ and a Sod $1^{-1-}$ male, randomising which male mated first. We hypothesised that sperm from Sod $1^{-1-}$ males may exhibit lower competitive ability under sperm competition. On examining embryos 14 days after mating, it was apparent that 24 females were pregnant. Surprisingly, when the embryos were genotyped, every single offspring was found to be sired by a Sod $1^{+/+}$male, regardless of which male mated with the female first. When Sod $1^{+/+}$males were the second to mate, the offensive sperm competition position, they sired $100 \%$ of the embryos; when Sod $1^{-/-}$males were in the offensive sperm competition position, they did not sire a single embryo (effect of male genotype on the percentage of offspring sired in the offensive position: $\chi^{2}=29.47,1$ d.f., $P<0.0001$; Fig. 1A). 

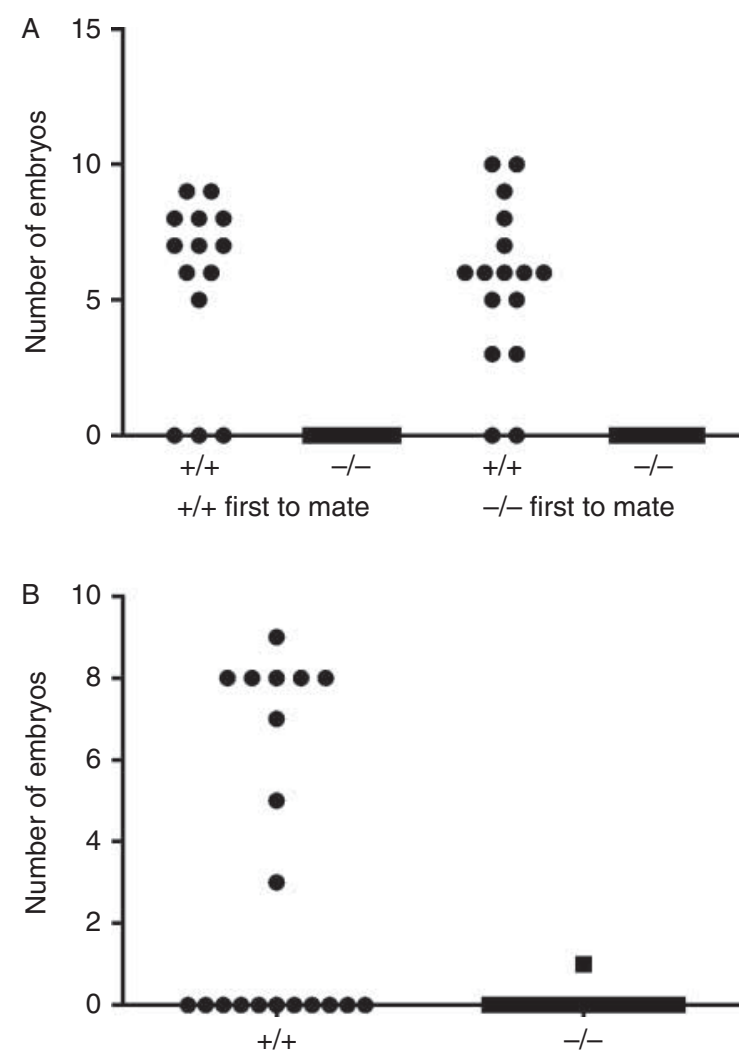

Figure 1 Reduced fertility rates in Sod1-deficient males. When compared with wild-type males $\left(^{+/+}\right)$, males deficient in Sod1 $\left(^{-/-}\right)$ had greatly reduced fertility, both when competing directly with a wildtype male to fertilise one female's eggs (A) and when mated separately with a CBA female (B). Each dot on the graph represents the number of embryos sired from an individual mating attempt.

To further understand the dramatic difference in fertilisation success between Sod1 $1^{+/+}$and Sod1 $1^{-/-}$ mice, males of each genotype were mated separately with CBA females. From 13 successful matings with Sod $^{-1-}$ males (e.g. where a copulatory plug was found), only one female was pregnant and carried just one embryo. This was a highly significant reduction in fertility when compared with the resulting embryos from 20 matings with equivalent Sod $1^{+/+}$males (effect of genotype on the number of embryos: $\chi^{2}=12.37$, 1 d.f., $P=0.0004$; Fig. 1B). This reduction in fertility was also apparent when conducting a binomial analysis to determine whether the mated females simply became pregnant or not (effect of male genotype on pregnancy: $\chi^{2}=5.86$, 1 d.f., $\left.P=0.015\right)$. Thus, the observed differences in fertilisation success may be attributable to the subfertility of $S o d 1^{-/-}$male mice when mated with CBA females in the experiments in this study.

\section{Mating behaviour}

Sod $1^{-/-}$males did not differ in their time until copulation when compared with Sod $1^{+/+}$males (effect of male genotype on time until copulation: $\chi^{2}=0.01,1$ d.f., $P=0.91$ ). Over the 160 trials conducted, there was a tendency for Sod1 $1^{-/-}$males to be less likely to successfully ejaculate in the window of opportunity allowed, which was $\sim 10 \mathrm{~h}$, although this effect was not significant (effect of male genotype on success in mating in the first male position: $\chi^{2}=3.58,1$ d.f., $P=0.059$ ). Thus, a difference in mating behaviour between the two male genotypes is unlikely to be the cause of such dramatic differences in fertility.

\section{Masses of reproductive organs and sperm motility}

At the end of the experiments, Sod $1^{-/-}$males exhibited minor reductions in the masses of their reproductive organs compared with Sod $1^{+/+}$males (Table 1). Their epididymides and seminal vesicles were of comparable size, but the mass of their testes was lower than that of the testes of Sod1 ${ }^{+/+}$males (Table 1).

To further ascertain the differences in reproductive physiology between Sod $1^{+/+}$and Sod $1^{-/-}$males, we examined sperm motility in a further set of these mice. The percentages of motile and progressively motile spermatozoa were much lower in epididymal sperm samples obtained from Sod1 ${ }^{-1-}$ mice (Table 2). A similar finding has recently been reported, where the percentage of motile and progressively motile sperm of Sod $1^{-1-}$ mice was lower after $7 \mathrm{~h}$ of incubation in a human tubal fluid medium when compared with that of sperm of Sod1 ${ }^{+/+}$males (Tsunoda et al. 2012). Furthermore, we report that average path velocity, curvilinear velocity and lateral head amplitude were also negatively affected in Sod $1^{-/-}$males (Table 2 ), which may further contribute to their reduced fertilising ability.

\section{Discussion}

Female mice mate multiply in the wild, and sperm from different males often compete to fertilise a female's eggs (Dean et al. 2006, Firman \& Simmons 2008). Animals in natural populations also exhibit genetic heterogeneity, highlighting that males will mate with females that are genetically unrelated to them. In spite of this, previous studies assessing fertility in Sod $1^{-1-}$ mice have been conducted under normal laboratory conditions, with genetically identical females of the same strain (Ho et al. 1998, Matzuk et al. 1998, Tsunoda et al. 2012). Our

Table 1 Differences in the weights of wild-type and Sod1-deficient males and their reproductive organs and differences between groups after correcting for body mass.

\begin{tabular}{lllcll}
\hline & \multicolumn{1}{c}{$+/+$} & \multicolumn{1}{c}{$-/-$} & d.f. & \multicolumn{1}{c}{$\boldsymbol{F}$} & $\boldsymbol{P}$ value \\
\hline Body mass & $29.84 \pm 0.82$ & $29.72 \pm 0.79$ & - & - & - \\
$\begin{array}{l}\text { Seminal } \\
\quad \text { vesicles }\end{array}$ & $0.226 \pm 0.014$ & $0.248 \pm 0.013$ & 1.19 & 2.43 & 0.14 \\
$\begin{array}{l}\text { Testes } \\
\text { Epididymis }\end{array}$ & $0.192 \pm 0.004$ & $0.182 \pm 0.004$ & 1.19 & 4.99 & 0.039 \\
\hline
\end{tabular}


Table 2 Sperm motility and related parameters in wild-type and Sod1-deficient males. Results in bold are significantly different between genotypes.

\begin{tabular}{|c|c|c|c|c|c|}
\hline & $+1+$ & $-1-$ & d.f. & $t$ & $P$ value \\
\hline Motility (\%) & $53.2 \pm 3.6$ & $32.9 \pm 4.5$ & 17 & 3.50 & 0.003 \\
\hline $\begin{array}{l}\text { Progressive } \\
\text { motility (\%) }\end{array}$ & $46.6 \pm 3.2$ & $25.1 \pm 3.6$ & 17 & 4.47 & $<0.001$ \\
\hline $\begin{array}{l}\text { Average path velocity } \\
\quad(V A P ; \mu \mathrm{m} / \mathrm{s})\end{array}$ & $59.6 \pm 2.4$ & $47.4 \pm 3.4$ & 17 & 2.83 & 0.012 \\
\hline $\begin{array}{l}\text { Straight line velocity } \\
\quad(\mathrm{VSL} ; \mu \mathrm{m} / \mathrm{s})\end{array}$ & $29.9 \pm 1.8$ & $25.1 \pm 2.2$ & 17 & 1.68 & 0.11 \\
\hline $\begin{array}{l}\text { Curvilinear velocity } \\
\quad(\mathrm{VCL} ; \mu \mathrm{m} / \mathrm{s})\end{array}$ & $130.9 \pm 3.7$ & $102.1 \pm 5.8$ & 17 & 4.05 & 0.001 \\
\hline $\begin{array}{l}\text { Lateral head } \\
\text { amplitude }(\mu \mathrm{m})\end{array}$ & $8.3 \pm 0.18$ & $7.2 \pm 0.19$ & 17 & 4.28 & 0.001 \\
\hline $\begin{array}{l}\text { Beat cross } \\
\quad \text { frequency }(\mathrm{Hz})\end{array}$ & $35.7 \pm 0.9$ & $34.3 \pm 0.9$ & 17 & 1.06 & 0.30 \\
\hline $\begin{array}{l}\text { Straightness } \\
\text { (VSL/VAP) }\end{array}$ & $45.8 \pm 1.3$ & $49.7 \pm 2.2$ & 17 & -1.52 & 0.15 \\
\hline Linearity (VSL/VCL) & $22.3 \pm 0.7$ & $24.4 \pm 1.4$ & 17 & -1.31 & 0.21 \\
\hline $\begin{array}{l}\text { Head elongation } \\
\quad \text { (minor/major axis) }\end{array}$ & $41.2 \pm 2.8$ & $43.6 \pm 2.16$ & 17 & 0.28 & 0.60 \\
\hline Head area $\left(\mu \mathrm{m}^{2}\right)$ & $10.6 \pm 0.5$ & $9.6 \pm 0.3$ & 17 & 0.09 & 0.98 \\
\hline
\end{tabular}

results indicate that more realistic mating procedures can reveal important phenotypic differences between Sod $1^{-/-}$mice and their Sod $1^{+/+}$siblings. When mated with the CBA strain of females, Sod $1^{-1-}$ males are virtually infertile.

The reduced fertility observed in the experiments of this study could be partly attributable to the smaller testis mass of $\mathrm{Sod}^{-1-}$ males. This trait, in particular, is expected to influence a male's ability to compete under sperm competition, due to its influence on the number of sperm that can be produced and transferred when mating (Parker et al. 1997, Ramm et al. 2005). Relative testis mass is strongly correlated with sperm competition risk across species in a variety of taxa (Parker et al. 1997, Ramm et al. 2005), with one theory predicting that testis mass and the consequential larger sperm number will evolve in situations of heightened sperm competition (Parker et al. 1997). Within species, testis size has been shown to correlate with reproductive success (Preston et al. 2003, Schulte-Hostedde \& Millar 2004). Although relative testis mass was reduced, it should be noted that there was some overlap in testis size when compared with Sod $1^{+/+}$males. Indeed, we found that Sod $1^{+/+}$ males with the smallest testes at the end of the experiments had still been capable of fertilising females in the last mating attempt. Therefore, some other aspect of reproductive function is likely to be impaired in Sod1 $1^{-/}$mice to cause such a drastic reduction in fertility.

A potentially more important factor influencing the fertility of Sod $1^{-1-}$ males may be their reduced sperm motility and path velocity. A relationship between average path velocity and litter size has been reported in another litter-bearing species (pigs), with sperm with low motility being predictive of a smaller litter size (Broekhuijse et al. 2012). In one species of fish
(Xiphophorus helleri) where multiple paternity and sperm competition are prevalent, average path velocity was also found to be a predictor of paternity (Gasparini et al. 2010). In addition to this, there are indications that average path velocity is negatively correlated with oxidative stress in human spermatozoa (Aitken et al. 1993, 1998). This suggests that the fertility of Sod1 ${ }^{-1-}$ mice may be impaired by decreased sperm swimming speed, which could be caused by an inability to protect spermatozoa against oxidative damage.

What may be the cause of the severely reduced fertility of $\operatorname{Sod} 1^{-1-}$ mice reported here when previous studies have found these mice to be as fertile as Sod $1^{+/+}$males? It is likely that the reproductive physiology of CBA females differs from that of C57BL/6 females, which Sod1 males have previously been mated with, and creates a more challenging environment for Sod1 ${ }^{-/-}$ mouse spermatozoa. The CBA and C57BL/6 strains of mice are known to differ in fertility, and reciprocal mating crosses between these strains have demonstrated that the smaller litter sizes of the $\mathrm{C} 57 \mathrm{BL} / 6$ strain are a consequence of the male genotype (Hager \& Johnstone 2003). Mating C57BL/6 males with CBA females leads to litter sizes that are smaller than those observed when CBA females are mated with a male of their own strain (Hager \& Johnstone 2003). The cause of this difference in fertility remains to be determined (Haig 2003), but increased oxidative stress with SOD1 deficiency could further reduce the ability of $\mathrm{C} 57 \mathrm{BL} / 6$ males to successfully fertilise a CBA female's eggs, possibly due to the effects of elevated oxidative damage on sperm function.

Laboratory strains of mice differ greatly in a variety of aspects of their reproductive physiology. These include not only overall fertility rates and litter sizes (Silver 1995), but also specific differences in the composition, size and number of their cumulus cells and zonae pellucidae (Krzanowska 1972), which may influence the ability of spermatozoa to successfully reach the egg plasma membrane (Primakoff \& Myles 2002). Compared with five other strains of laboratory mice, mice belonging to the CBA strain have a very tightly packed layer of cumulus cells surrounding their eggs and exhibit slow dispersal of these cells when treated with hyaluronidase (Krzanowska 1972, Wabik-Śliz 1997). It could, therefore, be expected that the reduced sperm motility of Sod $1^{-1-}$ males may limit their ability to penetrate this layer and reach the zona pellucida.

It has recently been demonstrated that $\mathrm{Sod} 1^{-/-}$mice have a reduced capability to penetrate the zona pellucida during IVF (Tsunoda et al. 2012), and therefore differences in the permeability of the zona pellucida between strains may be responsible for the greatly reduced fertility of Sod1 ${ }^{-1-}$ mice when mated with CBA females. CBA females tend to exhibit relatively rapid removal of the zona pellucida when treated with a pronase solution (Krzanowska 1972), although this does not necessarily mean that sperm will easily penetrate this 
barrier. In vitro, CBA males are highly capable of fertilising the eggs of CBA females while the zona pellucida is intact, while males of various other strains of laboratory mice, including $\mathrm{C} 57 \mathrm{BL} / 6$, have much lower fertility rates when mating with females of this strain (Kaleta 1977). If the zona pellucida is removed experimentally, the fertility rates of males of other strains of laboratory mice dramatically increase to levels observed in matings with CBA males (Kaleta 1977). This suggests that the interaction between $\mathrm{C} 57 \mathrm{BL} / 6$ sperm and the CBA zona pellucida is somewhat impaired when compared with normal fertilisation with both sexes of the CBA mouse.

To fully understand the causes of reduced fertilisation success in this study, in vitro experiments are now required where the sperm of Sod1 mice are allowed to fertilise eggs from both $\mathrm{C} 57 \mathrm{BL} / 6$ and CBA females. Experimental removal of the cumulus cells and zona pellucida may help reveal which stages of fertilisation are causing the observed results. In a broader sense, it may be important to determine whether the impaired fertilisation ability of Sod $1^{-/-}$males is also apparent when males are mated with strains of females other than C57BL/6 and CBA. This would give an insight into whether it is a peculiarity of the CBA female reproductive phenotype that makes fertilisation challenging for males with SOD1 deficiency or whether fertilisation in $\mathrm{C} 57 \mathrm{BL} / 6$ females is particularly easy. Ideally, experimental matings with recently wild-derived female mice, which are genetically representative of wild mice, would help to reveal the extent to which oxidative stress could impair fertility in natural populations.

The apparent normal fertility of Sod $1^{-1-}$ males when mating with females of the same strain has been demonstrated in three different laboratories over the last 15 years (Ho et al. 1998, Matzuk et al. 1998, Tsunoda et al. 2012). Although the phenotypes of Sod $1^{-1-}$ males seem consistent between laboratories and over time, we cannot exclude the possibility that some aspect of the environment in the experiments of this study caused their fertility to be lower than that reported by previous studies, and this contributed to their reduced fertility when mated with CBA females. Very little information regarding housing conditions has been provided by previous studies. In this study, it should be noted that males of both genotypes were singly housed in relatively large cages and were regularly exposed to the odour of other males and females, which could be different from the way that males were housed in the previous studies. We used this housing protocol to further create a more natural environment and also to stimulate normal reproductive behaviour. Exposing developing male mice to the odour of other males and females actually facilitates sperm production (Ramm \& Stockley 2009), so it is unlikely that this had a deleterious effect. Wild-type males also maintained a normal level of fertility in these experiments. Nonetheless, it would be interesting to experimentally test whether housing males in different environments influences the phenotypic effects of particular gene knockouts, particularly in relation to sperm function.

Antioxidant enzyme 'knockout' animals, such as the Sod $1^{-1-}$ model employed here, have been used extensively and successfully to understand the causal effects of oxidative stress on health and ageing (Perez et al. 2009, Salmon et al. 2010). These animals have also been studied to ascertain the role of these antioxidants in both male and female fertility. Many of these knockout animals apparently remain fertile, although the amount of data obtained from these animals is, at present, insufficient (Koppers 2012). Our results highlight that the antioxidant enzyme SOD1 may have a more important role in influencing male fertility in vivo than realised previously. Perhaps more importantly, our use of a different strain of laboratory mouse in mating trials highlights that altered fertility may be revealed when males are mated with females of different genetic backgrounds. Most strains of laboratory mice have been selectively bred for hundreds of generations, and this is likely to have led to some degree of coevolution between male and female reproductive physiology. We predict that mating males with phenotypes of interest to females of several different genetic backgrounds may give a better indication of factors that influence fertility in natural populations of animals.

\section{Declaration of interest}

The authors declare that there is no conflict of interest that could be perceived as prejudicing the impartiality of the research reported.

\section{Funding}

This project was funded by an ARC grant awarded to R C Brooks.

\section{Acknowledgements}

The authors thank Andrew Souter for help with sperm motility assays and BRC staff at the UNSW for help with animal maintenance.

\section{References}

Agarwal A, Saleh RA \& Bedaiwy MA 2003 Role of reactive oxygen species in the pathophysiology of human reproduction. Fertility and Sterility $\mathbf{7 9}$ 829-843. (doi:10.1016/S0015-0282(02)04948-8)

Aitken RJ \& Graves JAM 2002 Human spermatozoa: the future of sex. Nature 415 963-964. (doi:10.1038/415963a)

Aitken RJ, Harkiss D \& Buckingham D 1993 Relationship between iron-catalyzed lipid-peroxidation potential and human sperm function. Journal of Reproduction and Fertility 98 257-265. (doi:10.1530/jrf.0. 0980257) 
Aitken RJ, Gordon E, Harkiss D, Twigg JP, Milne P, Jennings Z \& Irvine DS 1998 Relative impact of oxidative stress on the functional competence and genomic integrity of human spermatozoa. Biology of Reproduction 59 1037-1046. (doi:10.1095/biolreprod59.5.1037)

Aitken RJ, Baker MA \& Sawyer D 2003 Oxidative stress in the male germ line and its role in the aetiology of male infertility and genetic disease. Reproductive BioMedicine Online 7 65-70. (doi:10.1016/S14726483(10)61730-0)

Allen E 1922 The oestrous cycle in the mouse. American Journal of Anatomy 30 297-371. (doi:10.1002/aja.1000300303)

Alvarez JG \& Storey BT 1995 Differential incorporation of fatty-acids into and peroxidative loss of fatty-acids from phospholipids of human spermatozoa. Molecular Reproduction and Development 42 334-346. (doi:10.1002/mrd.1080420311)

Alvarez JG, Touchstone JC, Blasco L \& Storey BT 1987 Spontaneous lipidperoxidation and production of hydrogen-peroxide and superoxide in human-spermatozoa superoxide-dismutase as major enzyme protectant against oxygen-toxicity. Journal of Andrology 8 338-348.

Beck JA, Lloyd S, Hafezparast M, Lennon-Pierce M, Eppig JT, Festing MFW \& Fisher EMC 2000 Genealogies of mouse inbred strains. Nature Genetics 24 23-25. (doi:10.1038/71641)

Beckman KB \& Ames BN 1998 The free radical theory of aging matures. Physiological Reviews 78 547-581.

Broekhuijse M, Sostaric E, Feitsma H \& Gadella BM 2012 Application of computer-assisted semen analysis to explain variations in pig fertility. Journal of Animal Science 90 779-789. (doi:10.2527/jas. 2011-4311)

Conrad M, Moreno SG, Sinowatz F, Ursini F, Kolle S, Roveri A, Brielmeier M, Wurst W, Maiorino M \& Bornkamm GW 2005 The nuclear form of phospholipid hydroperoxide glutathione peroxidase is a protein thiol peroxidase contributing to sperm chromatin stability. Molecular and Cellular Biology 25 7637-7644.

Dean MD, Ardlie KG \& Nachman MW 2006 The frequency of multiple paternity suggests that sperm competition is common in house mice (Mus domesticus). Molecular Ecology 15 4141-4151. (doi:10.1111/j.1365294X.200REF7 $=10.1002 / \mathrm{mrd} .1080420311$ )

Droge W 2002 Free radicals in the physiological control of cell function. Physiological Reviews 82 47-95. (doi:REF9=10.1038/71641)

Elchuri S, Oberley TD, Qi WB, Eisenstein RS, Roberts LJ, Van Remmen H, Jepstein CJ \& Huang TT 2005 CuZnSOD deficiency leads to persistent and widespread oxidative damage and hepatocarcinogenesis later in life. Oncogene 24 367-380. (doi:10REF11=10.2527/jas.2011-4311)

Elchuri S, Naeemuddin M, Sharpe O, Robinson WH \& Huang TT 2007 Identification of biomarkers associated with the development of hepatocellular carcinoma in CuZn superoxide dismutase deficient mice. Proteomics 7 2121-2129. (doi:10.1002/pmic.200601011)

Firman RC \& Simmons LW 2008 The frequency of multiple paternity predicts variation in testes size among island populations of house mice. Journal of Evolutionary Biology 21 1524-1533. (doi:10.1111/j.14209101.2008.01612.x)

Firman RC \& Simmons LW 2011 Experimental evolution of sperm competitiveness in a mammal. BMC Evolutionary Biology 1119. (doi:10.1186/1471-2148-11-19)

Gasparini C, Simmons LW, Beveridge M \& Evans JP 2010 Sperm swimming velocity predicts competitive fertilization success in the green Swordtail Xiphophorus helleri. PLoS ONE 5 e12146. (doi:10.1371/journal.pone. 0012146)

Hager R \& Johnstone RA 2003 The genetic basis of family conflict resolution in mice. Nature 421 533-535. (doi:10.1038/nature01239)

Hager R \& Johnstone RA 2006 The influence of phenotypic and genetic effects on maternal provisioning and offspring weight gain in mice. Biology Letters 2 81-84. (doi:10.1098/rsbl.2005.0403)

Haig D 2003 Behavioural genetics: family matters. Nature 421 491-492. (doi:10.1038/421491a)

Halliwell B \& Gutteridge JM 1999 Free Radicals in Biology and Medicine, Oxford, UK: Oxford University Press.

Ho YS, Magnenat JL, Bronson RT, Cao J, Gargano M, Sugawara M \& Funk CD 1997 Mice deficient in cellular glutathione peroxidase develop normally and show no increased sensitivity to hyperoxia. Journal of Biological Chemistry 272 16644-16651. (doi:10.1074/jbc.272.26. 16644)
Ho YS, Gargano M, Cao J, Bronson RT, Heimler I \& Hutz RJ 1998 Reduced fertility in female mice lacking copper-zinc superoxide dismutase. Journal of Biological Chemistry 273 7765-7769.

Kaleta E 1977 Influence of genetic factors on the fertilization of mouse ova in vitro. Journal of Reproduction and Fertility 51 375-381. (doi:10.1530/ jrf.0.0510375)

Klemme I \& Firman RC 2013 Male house mice that have evolved with sperm competition have increased mating duration and paternity success. Animal Behaviour 85 751-758. (doi:10.1016/j.anbehav. 2013REF30=10.1007/s00441-006-0297-y)

Koppers AJ 2012 Mitochondria as a source of ROS in mammalian spermatozoa. In Studies on Mens Health and Fertility, pp 21-40. Eds A Agarwal, RJ Aitken \& JG Alvarez. New York, NY, USA: Humana Press.

Koppers AJ, De luliis GN, Finnie JM, McLaughlin EA \& Aitken RJ 2008 Significance of mitochondrial reactive oxygen species in the generation of oxidative stress in spermatozoa. Journal of Clinical Endocrinology and Metabolism 93 3199-3207. (doi:10.1210/jc.2007-2616)

Kostrominova TY, Pasyk KA, Van Remmen H, Richardson AG \& Faulkner JA 2007 Adaptive changes in structure of skeletal muscles from adult Sod1 homozygous knockout mice. Cell and Tissue Research 327 595-605. (doi:10.1007/s00441-006-0297-y)

Koyama S \& Kamimura S 1999 Lowered sperm motility in subordinate social status of mice. Physiology \& Behavior 65 665-669. (doi:10.1016/ S0031-9384(98)00205-4)

Krzanowska H 1972 Rapidity of removal in vitro of the cumulus oophorus and the zona pellucida in different strains of mice. Journal of Reproduction and Fertility 31 7-14. (doi:10.1530/jrf.0.0310007)

Marsden HM \& Bronson FH 1964 Estrous synchrony in mice: alteration by exposure to male urine. Science $\mathbf{1 4 4}$ 1469. (doi:10.1126/science.144. 3625.1469REF36=10.1016/j.freeradbiomed.2006.01.036)

Matzuk MM, Dionne L, Guo QX, Kumar TR \& Lebovitz RM 1998 Ovarian function in superoxide dismutase 1 and 2 knockout mice. Endocrinology 139 4008-4011. (doi:10.1210/en.139.9.4008)

Mueller JL, Linklater JR, Ram KR, Chapman T \& Wolfner MR 2008 Targeted gene deletion and phenotypic analysis of the Drosophila melanogaster seminal fluid protease inhibitor Acp62F. Genetics 178 1605-1614. (doi:10.1534/genetics.107.083REF39=10.1016/j.bbagen. 2009.06.003)

Muller FL, Song W, Liu YH, Chaudhuri A, Pieke-Dahl S, Strong R, Huang TT, Epstein CJ, Roberts LJ, Csete M et al. 2006 Absence of CuZn superoxide dismutase leads to elevated oxidative stress and acceleration of age-dependent skeletal muscle atrophy. Free Radical Biology \& Medicine 40 1993-2004. (doi:10.1016/j.freeradbiomed.2006.01.036)

Parker GA 1970 Sperm competition and its evolutionary consequences in insects. Biological Reviews of the Cambridge Philosophical Society 45 525-567. (doi:10.1111/j.1469-185X.1970.tb01176.x)

Parker GA, Ball MA, Stockley P \& Gage MJG 1997 Sperm competition games: a prospective analysis of risk assessment. Proceedings of the Royal Society. Series B, Biological Sciences 264 1793-1802. (doi:10.1098/rspb.1997.0249)

Perez VI, Bokov A, Van Remmen H, Mele J, Ran QT, Ikeno Y \& Richardson A 2009 Is the oxidative stress theory of aging dead? Biochimica et Biophysica Acta 1790 1005-1014. (doi:10.1016/ j.bbagen.2009.06.003)

Preston BT, Stevenson IR, Pemberton JM, Coltman DW \& Wilson K 2003 Overt and covert competition in a promiscuous mammal: the importance of weaponry and testes size to male reproductive success. Proceedings of the Royal Society. Series B, Biological Sciences 270 633-640. (doi:10.1098/rspb.2002.2268)

Primakoff P \& Myles DG 2002 Penetration, adhesion, and fusion in mammalian sperm-egg interaction. Science $296 \quad 2183-2185$. (doi:10.1126/science.1072029)

Ramm SA \& Stockley P 2007 Ejaculate allocation under varying sperm competition risk in the house mouse, Mus musculus domesticus. Behavioral Ecology 18 491-495. (doi:10.1093/beheco/arm003)

Ramm SA \& Stockley P 2009 Adaptive plasticity of mammalian sperm production in response to social experience. Proceedings of the Royal Society. Series B, Biological Sciences 276 745-751. (doi:10.1098/rspb. 2008.1296) 
Ramm SA, Parker GA \& Stockley P 2005 Sperm competition and the evolution of male reproductive anatomy in rodents. Proceedings of the Royal Society. Series B, Biological Sciences 272 949-955. (doi:10.1098/ rspb.2004.3048)

Reaume AG, Elliott JL, Hoffman EK, Kowall NW, Ferrante RJ, Siwek DF, Wilcox HM, Flood DG, Beal MF, Brown RH et al. 1996 Motor neurons in $\mathrm{Cu} / \mathrm{Zn}$ superoxide dismutase-deficient mice develop normally but exhibit enhanced cell death after axonal injury. Nature Genetics 13 43-47. (doi:10.1038/ng0596-43)

Saleh RA \& Agarwal A 2002 Oxidative stress and male infertility: from research bench to clinical practice. Journal of Andrology 23 737-752.

Salmon AB, Richardson A \& Perez VI 2010 Update on the oxidative stress theory of aging: does oxidative stress play a role in aging or healthy aging? Free Radical Biology \& Medicine 48 642-655. (doi:10.1016/j. freeradbiomed.2009.12.015)

Schneider M, Forster H, Boersma A, Seiler A, Wehnes H, Sinowatz F, Neumuller C, Deutsch MJ, Walch A, de Angelis MH et al. 2009 Mitochondrial glutathione peroxidase 4 disruption causes male infertility. FASEB Journal 23 3233-3242. (doi:10.1096/fj.09-132795)

Schulte-Hostedde AI \& Millar JS 2004 Intraspecific variation of testis size and sperm length in the yellow-pine chipmunk (Tamias amoenus): implications for sperm competition and reproductive success. Behavioral Ecology and Sociobiology 55 272-277. (doi:10.1007/s00265-003-0707-z)
Sikka SC, Rajasekaran M \& Hellstrom WJG 1995 Role of oxidative stress and antioxidants in male infertility. Journal of Andrology 16 464-468.

Silver LM 1995 Mouse Genetics, Oxford: Oxford University Press.

Tsunoda S, Kawano N, Miyado K, Kimura N \& Fujii J 2012 Impaired fertilizing ability of superoxide dismutase 1-deficient mouse sperm during in vitro fertilization. Biology of Reproduction 87 1-6. (doi:10.1095/biolreprod.112.102129)

Wabik-Śliz B 1997 Phenotype and maturation rate of oocytes of chimaeric mice produced from two strains that differ in oocyte quality. Journal of Reproduction and Fertility 109 273-278. (doi:10.1530/jrf.0.1090273)

Zelko IN, Mariani TJ \& Folz RJ 2002 Superoxide dismutase multigene family: a comparison of the CuZn-SOD (SOD1), Mn-SOD (SOD2), and EC-SOD (SOD3) gene structures, evolution, and expression. Free Radical Biology \& Medicine 33 337-349. (doi:10.1016/S08915849(02)00905-X)

Received 28 May 2013

First decision 14 June 2013

Revised manuscript received 24 June 2013

Accepted 11 July 2013 